\title{
Will biological agents supplant systemic glucocorticoids as the first-line treatment for thyroid-associated ophthalmopathy?
}

\author{
Terry J Smith ${ }^{1,2}$ and Luigi Bartalena ${ }^{3}$ \\ ${ }^{1}$ Department of Ophthalmology and Visual Sciences, ${ }^{2}$ Division of Metabolism, Endocrinology and Diabetes, \\ Department of Internal Medicine, University of Michigan Medical School, Ann Arbor, Michigan, USA, and \\ ${ }^{3}$ Department of Medicine \& Surgery, University of Insubria, Endocrine Unit, ASST dei Sette Laghi, Varese, Italy
}

Correspondence should be addressed to T J Smith

Email

terrysmi@med.umich.edu

\begin{abstract}
In this article, the two authors present their opposing points of view concerning the likelihood that glucocorticoids will be replaced by newly developed biological agents in the treatment of active, moderate-to-severe thyroid-associated ophthalmopathy (TAO). TAO is a vexing, disfiguring and potentially blinding autoimmune manifestation of thyroid autoimmunity. One author expresses the opinion that steroids are nonspecific, frequently fail to improve the disease and can cause sometimes serious side effects. He suggests that glucocorticoids should be replaced as soon as possible by more specific and safer drugs, once they become available. The most promising of these are biological agents. The other author argues that glucocorticoids are proven effective and are unlikely to be replaced by biologicals. He reasons that while they may not uniformly result in optimal benefit, they have been proven effective in many reports. He remains open minded about alternative therapies such as biologicals but remains skeptical that they will replace steroids as the first-line therapy for active, moderate-to-severe TAO without head-to-head comparative clinical trials demonstrating superiority. Despite these very different points of view, both authors are optimistic about the availability of improved medical therapies for TAO, either as single agents or in combination. Further, both agree that better treatment options are needed to improve the care of our patients with active moderate-to-severe TAO.
\end{abstract}

\section{Introduction}

Graves' disease (GD) is an organ-specific autoimmune disorder and the most common cause of hyperthyroidism, particularly in thyroid-replete geographical areas (1). It has an approximate prevalence of $2 \%$ in women and $0.3 \%$ in men and an incidence of 21 new cases/100 000/ year (2). Thyroid-associated ophthalmopathy (TAO), also known as Graves' ophthalmopathy, orbitopathy or thyroid eye disease, is the most consequential extrathyroidal manifestation of GD (3). In the last few decades, the prevalence of TAO appears to have decreased in patients with recent-onset GD $(4,5)$. Most cases have mild and non-progressive (or remitting) TAO (6). This is likely the positive consequence of early diagnosis, improved management, closer interactions between endocrinologists and ophthalmologists and development of early referral patterns to specialized centers (7). The estimated prevalence of TAO in Europe is about 10/10 000 persons, but the prevalence of variants, such as hypothyroid TAO, TAO associated with thyroid dermopathy or acropachy and asymmetrical or unilateral TAO are considerably below the European threshold for rarity (5/10 000 persons), ranging from 0.5 to $1.5 / 10$ 000 persons (8). However, moderate-to-severe forms of TAO with varying degrees of inflammation (activity) and severity may already be evident at presentation of GD (Fig. 1). Alternatively, TAO might develop in the course 


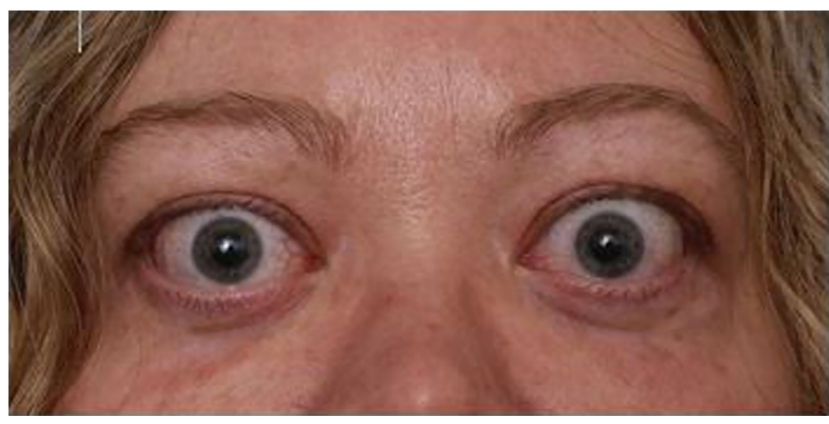

\section{Figure 1}

Clinical presentation of TAO. A case of active TAO exemplifying an individual with dominant proptotic disease, manifesting eyelid retraction, and mild inflammation.

of GD, possibly due to differences in genetic background or to the presence of one or more risk factors. These include tobacco smoke exposure, poorly controlled thyroid dysfunction, oxidative stress or high TSH receptor (TSHR) antibody (TRAb) levels $(9,10)$. Overt TAO is a disfiguring and invalidating disease substantially reducing the quality of life. This results from changes in appearance (exophthalmos, periorbital soft tissue swelling) and abnormal visual function (diplopia, pain, altered visual acuity) (11).

Care of moderate-to-severe TAO remains suboptimal and represents an unmet public health need (12). Several years ago, one of us (LB) concluded rather pessimistically in his review of the management of TAO with the following lament: 'I might say that GO (TAO) is (in many instances) a surgical disease, and the only role of medical treatment is to abate inflammation and inactivate the disease, making it possible to send the patient to the surgeon(s) earlier' (13). However, recent years have witnessed a progressive clarification of our understanding of the pathogenesis of TAO $(14,15)$. New insights make it possible to foresee the use of targeted medical therapies that might revolutionize the management of TAO and dramatically improve its outcome (16).

The initial, active phase of TAO is dominated by inflammation and edema and typically lasts for up to 3 years (17). This activity can culminate in fibrosis which is believed to be essentially irreversible. Thus, medical therapy for TAO has largely been aimed at the active phase of the disease. The mechanisms underlying development of TAO are complex and intimately intertwined with the related autoimmunity occurring within the thyroid gland (18). Connectivity between glandular and orbital manifestations of GD remains shrouded in uncertainty, in large part by the historical absence of animal models exhibiting high fidelity with the human disease. Recent advances in preclinical modeling are encouraging but remain imperfect (19). Another barrier to solving its pathogenesis concerns the wide variability among patients with regard to their clinical presentation of $\mathrm{TAO}$ and the relative rarity of the disease (18). At the core of GD is loss of immune tolerance to the TSHR and the generation of autoantibodies directed at the receptor protein (20). These antibodies can stimulate the TSHR or block its activity $(21,22)$. Accumulating evidence supports the participation of TSHR and these pathogenic autoantibodies in the development of TAO. But unlike their roles in the hyperthyroidism of GD, the precise nature of their involvement in TAO is not fully understood. Besides TSHR, the insulin-like growth factor-I receptor (IGF-IR) has been proposed as another important component of the immune responses occurring in TAO (15). Autoantibodies targeting IGF-IR have been detected in patients with GD $(23,24,25)$ and in experimental rodent models following immunization with a TSHR A subunit-encoding plasmid (19). These autoantibodies do not appear to be disease specific in that they have been detected in rheumatoid arthritis (RA) as well (26). Other investigators have failed to detect these anti-IGF-IR antibodies in increased levels or having IGF-IR-activating activities in GD $(27,28)$. In GD, IGF-IR is overexpressed by orbital fibroblasts, $\mathrm{T}$ and $\mathrm{B}$ cells $(29,30,31)$. In addition, TSHR and IGF-IR have been shown to form both physical and functional protein complexes (29). Moreover, inhibiting IGF-IR activity attenuates signaling initiated by either TSHR or IGF-IR. Thus, the actions of pathological autoantibodies associated with GD and TAO, regardless of which receptor they target, can be modulated through inhibition of IGF-IR. This realization led to the rationale for therapeutically targeting IGF-IR in this disease complex.

In $\mathrm{TAO}$, the orbit becomes infiltrated to varying degrees with professional immune cells, including $\mathrm{T}$ and B-lymphocytes, monocytes and mast cells $(32,33,34)$ (Fig. 2). Orbital fibroblasts inhabiting the TAO orbit (hereafter referred to as GD-OF) exhibit striking characteristics that distinguish them from fibroblasts in healthy orbits (35). We now know that among the differences in cellular makeup and behavior of fibroblasts found in TAO is the unique presence of $\mathrm{CD}^{2} 4^{+}$fibrocytes that masquerade as $\mathrm{CD}_{3} 4^{+} \mathrm{OF}$ and that reside among other fibroblasts in the population of GD-OF but exhibit the $\mathrm{CD}_{3} 4^{-} \mathrm{OF}$ phenotype $(36,37)$. Fibrocytes derive from the monocyte lineage (36). They express several proteins initially thought to be confined to the thyroid gland; among these is TSHR $(38,39)$. These proteins are under the control in fibrocytes 


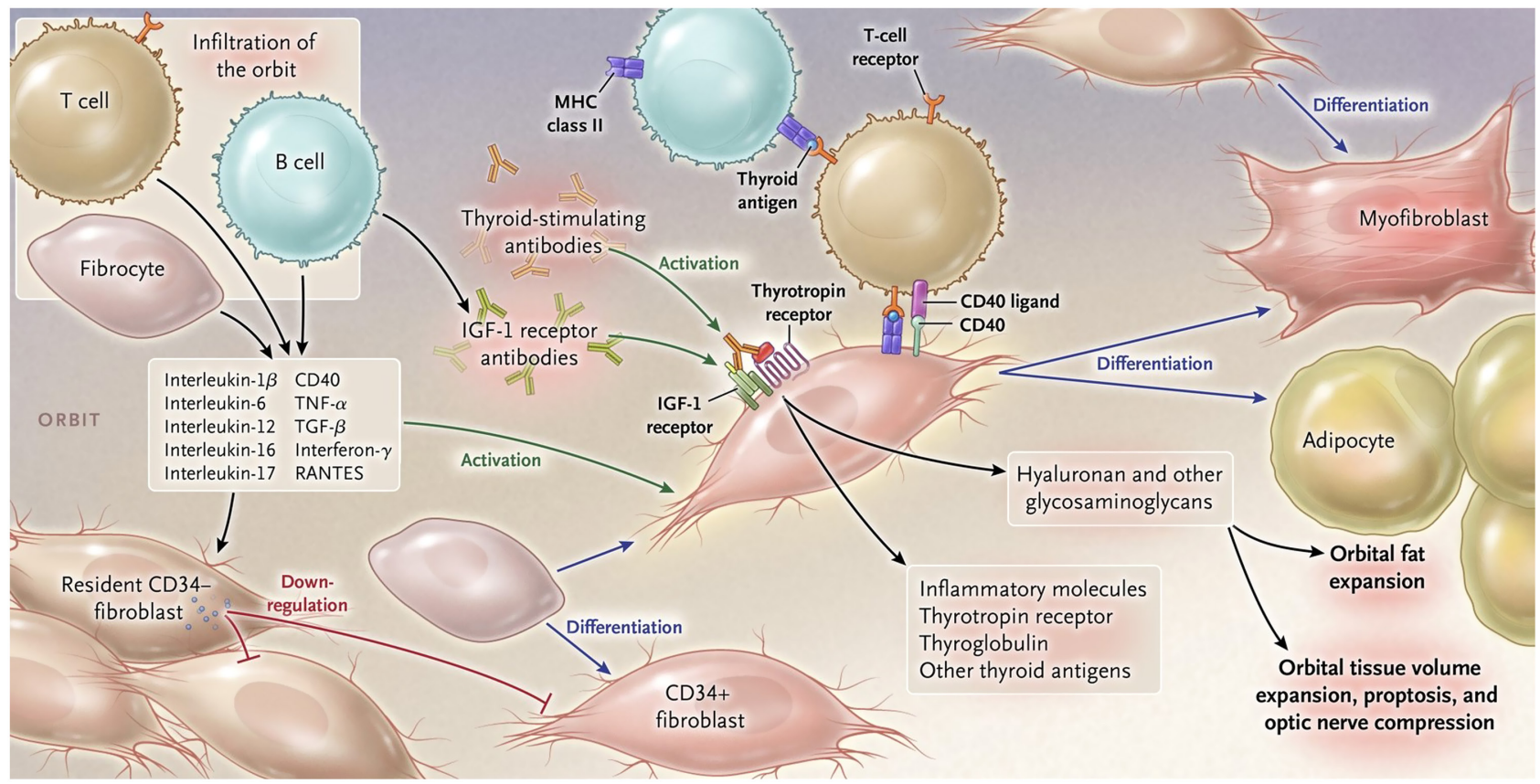

\section{Figure 2}

Proposed theoretical model of TAO pathogenesis. Bone marrow-derived CD34+ fibrocytes circulate in Graves' disease at higher levels. They express several thyroid autoantigens, including thyrotropin receptor (TSHR), thyroglobulin, thyroperoxidase and sodium-iodide symporter. Fibrocytes present antigens to T cells through Class $2 \mathrm{MHC}$. These T cells endorse B cell production of IgG1, can differentiate into CD34+ fibroblasts, myofibroblasts and adipocytes. CD34+ fibroblasts are held in check by residential CD34- fibroblasts. When activated, CD34+ fibroblasts generate several proinflammatory or anti-inflammatory cytokines, including interleukins $1 \beta, 6,8,10,12,16$, tumor necrosis factor $\alpha$ and regulated on activation, normal T expressed and secreted (RANTES), CXCL-12 and CD40 CD154. Both infiltrating and residential cells express insulin-like growth factor-I receptor (IGF-IR), suggesting that this tyrosine kinase might represent a therapeutic target. Alternatively, levels and actions of cytokines could be attenuated. Fibroblasts synthesize hyaluronan, potentially expanding tissue volume. Orbital fat can also expand in TAO. From Smith and Hegedus (1). Copyright @ (2016) Massachusetts Medical Society. Reprinted with permission.

of the autoimmune regulator protein. When activated, fibrocytes also express several cytokines implicated in the development of TAO. These include IL-1 $\beta$, IL- 6 and TNF- $\alpha(40,41,42)$. They can undergo differentiation into adipocytes, myofibroblasts, chondrocytes and osteoblasts, depending on molecular environment surrounding them within tissues $(43,44)$. Several factors have been shown to influence fibrocyte differentiation; Th1 cytokines and lumican enhance while Th2 cytokines $(45,46)$, Slit2 (47) and serum amyloid P (48) inhibit this process. These inhibitors of fibrocytes may play particularly important roles in the TAO orbit. For instance, CD34- OF express and release Slit2, potentially governing the behavior of $\mathrm{CD}_{3} 4^{+}$OF. It has been shown that Slit2 substantially reduces the expression in fibrocytes of autoantigens associated with GD and MHC II (49). By virtue of their phenotypic attributes, fibrocytes and derivative $\mathrm{CD} 34^{+} \mathrm{OF}$ may represent important therapeutic targets for TAO.

\section{Will biological agents supplant systemic glucocorticoids as the first-line treatment for TAO? Yes, inevitably with the passage of time (Terry J Smith)}

In this section, I will attempt to convince you that biological agents represent promising treatment options that will inevitably alter our management of active, moderate-to-severe TAO. While glucocorticoids can offer symptomatic relief of discomfort in TAO and can help temporize in ocular emergencies such as compressive optic neuropathy, they frequently fail to work or are only of marginal efficacy. Further, most experts agree that they do not alter the natural course of the disease or change its ultimate outcome; therefore, they do not appear to lessen the need for surgical rehabilitation once the stable phase of TAO has been reached. In addition, they are potentially dangerous agents with well-recognized side effect profiles. 
Thus, we need better therapeutic options than systemic glucocorticoids.

The relatively recent introduction of monoclonal antibody therapy in RA and related disorders is frequently considered to represent the birth of a new paradigm in medicine. But early examples of biological therapy began with the application of leeches to the ailing human body and attempts to immunize. More recent examples, especially those aimed at autoimmune diseases date back to the early 1930s. It was then that blood transfusions were first employed as therapy in RA (50). Later, autotransplantation of the joint capsule was performed as a strategy for desensitizing patients with RA (51). Although none of these methods has proven effective or safe and the simplistic concepts underlying their use reflect the relative naïveté of a bygone period, far more specific and evidence-based approaches have now emerged. The following description of iterative progress in the treatment of autoimmune diseases will hopefully provide a persuasive argument for the use of biological agents in TAO. Although only recently introduced into the realm of GD and TAO, a number of encouraging developments have provided reason for optimism that effective and safe therapies will soon emerge from this evolving therapeutic approach. Given the lack of convincing evidence that glucocorticoid therapy alters the long-term clinical course of TAO or reduces the need for remedial surgeries, in my view, we must look elsewhere for treatments the impact of which is more meaningful.

\section{Successful precedent: tumor necrosis factor $\alpha$ has become an important therapeutic target in RA and its many allied diseases}

The last two decades have witnessed a developmental wave of immunological agents that therapeutically target cytokines, their receptors and other molecules implicated in autoimmune disease pathogenesis. Among the first and most impactful have been biological molecules aimed at the tumor necrosis factor $\alpha(\mathrm{TNF}-\alpha)$ pathway. The initial strategy for downregulating or otherwise interrupting the TNF- $\alpha$ pathway in RA involved the administration of etanercept, a recombinant tumor necrosis factor receptor: Fc fusion protein (52) to 89 patients with persistent active disease resistant to methotrexate. The drug was found to be superior to placebo in patients receiving methotrexate. Seventy-one percent of the patients treated with both etanercept and methotrexate met the ACR 20 criteria, while 27 percent of those receiving placebo and methotrexate responded $(P<0.001)$. Another approach came with the concept of directly intercepting the TNF- $\alpha$ molecule. This was accomplished with the development of adalimumab (Humira), a fully human monoclonal antibody that targets and neutralizes the TNF- $\alpha$ molecule (53). It was examined for efficacy and safety in a placebocontrolled clinical trial assessing the effects of the drug in 271 patients with active RA despite their continued treatment with methotrexate (54) (ARMADA trial). A significantly higher rate of primary response was achieved in those receiving adalimumab plus methotrexate compared to methotrexate alone $(P<0.001)$. Since these early developments, several other molecules targeting TNF- $\alpha$ have appeared in the marketplace and their impact on current care of RA and its allied diseases has been enormous and game changing.

Besides the wave of agents altering the TNF- $\alpha$ pathway, a number of drugs, the actions of which are unrelated to TNF- $\alpha$, have emerged as potential therapeutics in autoimmune diseases. Among the notable examples is eculizumab (Soliris), a monoclonal antibody targeting the terminal component 5 of the complement cascade (55). Satralizumab has recently been found to improve the clinical behavior of patients with neuromyelitis optica, a disease where IL-6 is currently thought to play a dominant pathogenic role (56). A very recent report has demonstrated remarkable reduction in disease relapse in neuromyelitis optica (57). The CD40/CD40 ligand pathway has been examined as a potential target in autoimmune diseases and several different molecules are in various stages of development (58). Its involvement in $\mathrm{B}$ cell class switching and $\mathrm{T}$ cell-B cell crosstalk provide the rationale for investigating this molecular bridge in these diseases.

\section{IL-6 as a target for biological agents in autoimmune diseases}

The IL-6 pathway serves important roles in the immune response (59). These include supporting B cell development and function and $\mathrm{T}$ cell polarization to Th17. Thus, IL-6 and its receptor represent an important immunologic crossroad that can be targeted therapeutically. Given its broad involvement, this cytokine has been implicated in the pathogenesis of several autoimmune diseases. Satralizumab and tocilizumab target the IL-6 receptor, blocking its activation $(60,61)$. They were developed as a treatment for RA but since its introduction to the clinical 
trial space, these drugs have exhibited promising activity in systemic lupus erythematosis, giant cell arteritis, Sjögren syndrome, Crohn's disease and neuromyelitis optica $(62,63,64,65)$. The drug is currently being evaluated in systemic sclerosis; however, emerging roles identified for other cytokines such as IL-13 have yielded questions concerning whether interrupting the IL-6 pathway will prove effective. Early encouraging findings suggest that tocilizumab may be effective in SLE. A potential drawback of the drug concerns adverse effects in the liver (66).

\section{Initial migration to biological therapies in GD and TAO}

Among the earliest biological drug candidates to be evaluated in GD was rituximab, a B cell-depleting monoclonal antibody directed at CD20. The drug was developed for the treatment of non-Hodgkin's B cell lymphoma (67). The scope of uses for rituximab has expanded considerably since its importance became established in cancer. The drug has proven effective in autoimmune diseases, most notably in RA, neuromyelitis optica, systemic lupus erythematosus and ulcerative colitis (68). Its insinuation in the therapy of GD was first proposed by Hasselbalch (69). Several case reports and small series appeared examining the efficacy of B cell depletion in both the hyperthyroidism of GD and TAO $(70,71,72,73)$. With regard to the former, a recently announced study will involve prospectively assessing rituximab as an adjuvant therapy in 27 young patients (age range 12-20 years) with hyperthyroidism in the United Kingdom (74). The combination of anti-thyroid medication during a 12-month course and rituximab administered as a single dose will be examined for its impact on remission at 2 years. Whether hyperthyroidism in GD should be targeted primarily for B cell depletion in GD was questioned in the past (75), given the other treatment options now available and the potential for serious side effects. Limited evidence thus far reported suggests that rituximab therapy in GD uncomplicated by TAO is probably unwarranted (75).

Initially encouraging experiences with rituximab use in small cohorts of patients manifesting active, moderateto-severe TAO prompted larger, controlled studies. Its efficacy and safety were examined in two prospective, simultaneously reported clinical trials $(76,77)$. Both trials were prospective, double-masked and had a primary response endpoint of greater than two points in the clinical activity score (CAS). Both studies were conducted at a single site, one in Italy and the other in the United States. When compared with placebo, rituximab failed to show benefit over placebo at 24 weeks in the study of 25 enrolled patients conducted at the Mayo clinic (76). The other study in Milan involved 32 patients who were randomized to receive either rituximab or methylprednisolone (77). Study participants receiving rituximab exhibited greater improvement in CAS than those treated with methylprednisolone. Proptosis failed to improve in patients receiving rituximab, methylprednisolone or placebo in either study. These very different results with rituximab may have resulted from considerable disparities in duration of disease prior to enrolment, variations in anti-TSHR antibody levels differences in participant ages. Thus, unambiguous clinical benefit of anti-CD20 therapy in moderate-to-severe, active TAO has yet to be demonstrated. Further studies with rituximab or potentially anti-CD19 drugs (which may be more effective as they also target plasmablasts) will be required. As with many of the antibody driven autoimmune diseases where rituximab has proven effective, autoantibody level reduction does not appear to mediate the beneficial effects of the drug.

\section{Biologicals targeting cytokines and their potential in TAO}

Among the biologicals in wide clinical use for autoimmune diseases are anti-cytokine agents. These include monoclonal antibodies interrupting the TNF- $\alpha$ (78) and IL-6 $(60,63)$ pathways. A limited number have been repurposed for TAO, most notably tocilizumab has been studied in moderate-to-severe TAO in two separate trials. In an open-label, uncontrolled study of 18 patients with active TAO, Perez-Moreiras et al. assessed visual acuity, proptosis, CAS, TSI levels and ocular motility (79). They found that all patients exhibited improved CAS, 13 patients had a reduction of proptosis (mean $3.92 \mathrm{~mm}$ ), 15 had improved ocular motility and 7 patients had resolution of diplopia. Importance of those findings is difficult to assess given the absence of controls. A subsequent, multicenter study from many of the same investigators examined 32 patients with glucocorticoidresistant, moderate-to-severe TAO in a randomized, placebo-controlled trial (80). The primary outcome, proportion of patients with improved CAS $>2$ at week 16 , was met in $93.3 \%$ of patients receiving active drug compared to $58.8 \%$ receiving placebo $(P=0.04)$. Those receiving tocilizumab also had a greater reduction in 
proptosis $(1.5 \mathrm{~mm})$ than did patients in the placebo group $(0.0 \mathrm{~mm}, P=0.01)$, but this relatively modest effect may not prove durable. The authors considered that their study was limited by the relatively small recruitment size and the potentially long interval between initial disease presentation and enrolment in the trial. They also voiced the possibility that the treatment period prior to assessment of the primary outcome measure (16 weeks) may have been inadequate for maximal benefits to occur.

\section{TSHR as a therapeutic target in GD}

The rationale for targeting the TSHR as a therapy for hyperthyroidism in GD stems from its central pathogenic role in the thyroid component of GD. Activating autoantibodies directed at TSHR results in the characteristically unregulated thyroid activity found in the disease (20). The presumption that targeting the relatively low-level expression of TSHR in orbital connective tissues would prove effective in TAO stems largely from in vitro studies implicating the receptor in the activation of GD-OF and fibrocytes $(81,82)$. Several studies have demonstrated that TSHR signaling can activate specific cytokine gene expression in these cell types $(41,82)$. Several molecules targeting TSHR, including both small molecules and monoclonal antibodies, have been developed in the recent past and some are now entering into early clinical investigation. With regard to the former, Org41841 is a partial agonist for both TSHR and the leutinizing hormone receptor (83). This lack of target specificity may complicate its road to clinical utility. Among other small molecules are those that can block thyroid-stimulating immunoglobulin actions in vitro and can also exert inhibition in vivo in small animal models $(84,85)$.

Besides small molecules, several anti-TSHR antibodies have shown receptor-blocking activities (44, 86, 87). Included among these are inverse agonists, which inhibit constitutive TSHR activities (88). K1-70, a TSHR-blocking antibody (44), has exhibited activity in vivo in rats and is currently undergoing evaluation in an early phase clinical trial. It is possible that targeting TSHR directly may provide a solution for both the hyperthyroidism as well as the ocular manifestations of GD. The widespread expression of TSHR in tissues peripheral to the thyroid, even at the generally lower receptor density thus far identified, makes off-target consequences of its inhibition/blockade a safety concern that will need to be empirically tested in both preclinical studies and clinical trials.

\section{Insinuation of IGF-IR into the pathogenesis of TAO has resulted in a promising antigen-specific therapy}

A relationship between the TSHR and IGF-I pathways was first described by Ingbar and his colleagues (89) when they found that IGF-I could enhance the actions of TSH on thyroid cells in cultures. Subsequently, IgGs collected from patients with $\mathrm{TAO}$ were found to displace radiolabeled IGF-I from the cell surface of fibroblasts, although the identity of the binding site(s) was not characterized initially (90). Using IGF-I analogs specific for IGF-IR, Pritchard et al. demonstrated that these autoantibodies bind to IGF-IR and could initiate signaling, actions were attenuated by blocking IGF-IR or downregulating its expression in GD-OF from patients with TAO (23). Further, IGF-IR is over-expressed by GD-OF, B and T cells in GD $(30,91)$ and TSHR and IGF-IR form a signaling complex (29). Inhibition of IGF-IR activity attenuates signaling downstream from both IGF-IR and TSHR. These findings represented the rationale for initiating a multicenter therapeutic trial of an IGF-IR inhibitory monoclonal antibody. Teprotumumab was repurposed from its initially intended use in various forms of cancer where it had proven generally ineffective (92).

The first trial examining potential therapeutic activity of IGF-IR inhibition in TAO began recruiting patients in 2013. The results of this study were reported in 2017 (93). The study enrolled 88 patients with active, moderate-to-severe TAO randomly assigned (1:1) to receive either teprotumumab, a $\beta$-arrestin biased IGF-IR agonist, or placebo. Patients underwent IV infusions every 3 weeks for a total of eight doses over a 24-week period. The primary response, assessed at week 24 , was an aggregate of $\geq 2$-point reduction of the CAS (7-point scale) and reduction of $\geq 2 \mathrm{~mm}$ of proptosis in the more severely affected eye without a similar worsening in the fellow (contralateral) eye. Measured as continuous variables, secondary endpoints included reduction in CAS, proptosis, improvement in diplopia and changes in quality of life using a validated questionnaire. Baseline CAS in the teprotumumab group was 5.1. 29/42 patients receiving teprotumumab in the intention-to-treat cohort achieved primary response at week 24 , compared to $9 / 45$ of those receiving placebo $(P<0.001)$. Time to first response was considerably shorter in the teprotumumab group. The effects of the drug were rapid; $18 / 42$ patients receiving active drug responded at week 6 compared to $2 / 45$ of those in the placebo group $(P<0.001)$. The mean 
reduction in CAS in the active drug-receiving group was four points while that of proptosis was $-2.46 \mathrm{~mm}$ at 24 weeks. In an analysis grading response magnitude, more patients receiving the active drug achieved a reduction of $\geq 3$ points in CAS and $\geq 3 \mathrm{~mm}$ of proptosis $(P<0.001$ versus placebo). 17/42 patients receiving teprotumumab had $\geq 4 \mathrm{~mm}$ proptosis reduction while 0 in the placebo group achieved that level of response. Efficacy in the fellow eye was similar to that in the study eye with regard to both proptosis and CAS improvement. The effects of teprotumumab appear to be durable as recent follow-up findings suggest that many responders experience sustained improvement, months following the treatment period (94). Thus, the results with teprotumumab are comparable to the best results thus far attained with surgical decompression (95).

The safety profile of teprotumumab appears to be favorable after a 1-year follow-up per protocol and as long as a 72-week voluntary follow-up. Muscle cramping, diarrhea, hyperglycemia, dysgeusia, paresthesia, headache or hearing impairment was experienced by at least $5 \%$ of patients receiving teprotumumab, while these occurred in fewer patients receiving placebo. A single patient with recently diagnosed ileitis/colitis was treated for a flare of inflammatory bowel disease while receiving teprotumumab. Worsening of preexisting diabetes occurring while receiving teprotumumab was the only drug-related adverse event and was remedied by increasing diabetes medicine. Importantly, those necessary adjustments in glycemic control medications became unnecessary and dosages returned to baseline levels following the end of the treatment phase. A second, phase $3 \mathrm{~b}$, trial of teprotumumab was performed and the topline results were made public very recently https:// www.healio.com/ophthalmology/oculoplastics/news/ online/.../teprotumumab-for-treatment-of-thyroid-eyedisease-meets-endpoints-in-phase-3-study. In that study, the primary response endpoint, reduction in proptosis in the more severely affected eye, was reached in $82.9 \%$ of the patients receiving teprotumumab, while $9.5 \%$ of those receiving placebo achieved this response $(P<0.001)$. All secondary endpoints were met (at week 24 ), including overall responder rate (primary endpoint in the phase 2 study), percent of participants with a CAS value of 0 or 1 , percent of patients with a change from baseline of at least one grade in diplopia, mean change in proptosis from baseline and mean change in Graves' Ophthalmopathy Quality of Life score from baseline.

The results of the two clinical trials for teprotumumab carry substantial mechanistic and therapeutic implications for GD and TAO. They suggest that the IGF-IR is an integral component of disease pathogenesis. Further, it may play analogous roles in other autoimmune diseases. The remarkable effectiveness and safety displayed by the drug suggests that teprotumumab could become the standard first-line therapy for moderateto-severe TAO. Whether the drug might also benefit patients with disease that has entered into the stable phase remains an open question. In addition, the potential for teprotumumab to reduce necessary surgical rehabilitation and offer long-term durability remains to be determined.

\section{The road beyond initial investigation of biologicals - restoration of immune tolerance in GD and TAO}

Biologics as therapy in TAO represent the initial steps in an iterative process of refining our approach to this disease. But they should be viewed as intermediate in the spectrum of therapy. Ultimately, treating TAO will involve the restoration of immune tolerance, sparing patients' long-term exposure to immunomodulatory agents. Among the early studies thus far performed are those examining the impact of cyclic peptides from the TSHR in the leucine-rich domain. These were found to lessen the disease phenotype of mice immunized with adenovirus encoding TSHR289 (96, 97). Studies performed in HLA-DR3 transgenic mice utilized a mixture of two immunodominant regions of the TSHR in technology termed antigen-processing-independent epitopes (Apitopes) demonstrated suppression of both $\mathrm{T}$ cell and antibody responses to the receptor (98). Efforts to induce immune tolerance toward TSHR have found their way into early clinical trials. ATX-GD-59 is a peptide-based strategy that has been reported as having an encouraging response profile and acceptable safety in a phase 1 trial (99).

To summarize my comments, moderate-to-severe, active TAO remains a vexing and poorly cared for disease that has relied on systemic glucocorticoids as a mainstay of medical treatment for several decades. Given the frequency of patients in whom these drugs have proven ineffective and the poor prospects for them to exhibit a modifying effect on the clinical course of the disease, the recently developed, highly specific biologics now offer unprecedented opportunity to provide better care, potentially with much improved safety profiles. 


\section{Will biological agents supplant systemic glucocorticoids as the first-line treatment for moderate-to-severe and active TAO? Maybe, but I am not convinced (yet) (Luigi Bartalena)}

Remodeling occurring in the orbit of patients with TAO and eventual fibrotic changes make it clear that there is no hope that whatsoever medical treatment be effective if it is not carried out early, probably very early in the course of the disease. Although it is somehow arbitrarily stated that the natural course of TAO lasts about 2-3 years, this concept can be applied only to mild forms of the disease. We really do not know how long is the 'natural' duration of inflammation (activity) of moderate-to-severe forms, because they are treated as soon as possible, and, therefore, their natural course is modified by therapies. Therefore, we cannot exclude that patients treated within 1 year after the onset of TAO, the traditional limit beyond which non-surgical therapies are believed to be less effective, be already poorly responsive to treatment. This uncertainty and differences in the clinical setting and selection of patients may, at least partly, explain the heterogeneity of results of a given treatment. This premise is instrumental to explain the concept that in a field with limited evidence such as TAO, if one states that a novel treatment is better than an old one, this statement should stem from randomized clinical trials comparing the old (and established) therapy and the new therapy exactly in the same clinical setting and using the same outcome measures. Otherwise, this is only an indirect inference.

Glucocorticoids are an old and well-established treatment for the management of TAO since several decades (100). They are used in two different situations (Table 1). Low-dose and short-term oral prednisone is given immediately after radioactive iodine (RAI) therapy for Graves' hyperthyroidism (steroid prophylaxis) to prevent de novo occurrence or progression of TAO in at-risk patients, especially smokers, patients with high TRAb levels or with preexisting mild TAO of short duration (13). Glucocorticoids are very effective in this preventive action and substantially devoid of relevant side effects (101).

The other clinical setting, on which this debate paper is focused, is represented by moderate-to-severe and active TAO. The only guideline published insofar in the field of TAO states that intravenous (iv) glucocorticoids (GCs) should be considered the first-line treatment for moderateto-severe TAO (102). Because of the inflammatory and autoimmune nature of $\mathrm{TAO}$, it is not surprising that glucocorticoids be an effective treatment for TAO. Their effects are exerted through genomic and non-genomic actions (103). Genomic actions imply binding of glucocorticoids to its cytosolic receptor, translocation of the glucocorticoid receptor complex to the nucleus, binding to specific response elements on DNA, thereby activating transcription of anti-inflammatory protein genes and inhibiting transcription of proinflammatory protein genes (104). This process ultimately causes increased synthesis of anti-inflammatory proteins and decreased synthesis of proinflammatory proteins, respectively. These genomic effects are not immediate and require hours to days (104). However, glucocorticoids also have very fast non-genomic actions, occurring within seconds to minutes and related to physicochemical changes of the cellular membrane or interaction with membrane-bound receptors, thereby leading to cellular membrane stabilization (105). Several functions of fundamental cells for the inflammatory/autoimmune reactions, such as dendritic cells, macrophages, T-lymphocytes and B-lymphocytes are attenuated or abolished by glucocorticoids (106). Treatment with intravenous glucocorticoids has been associated with a rapid inhibition of plasma cells and abrogation of circulating dendritic cells (107), as well as with a reduction in serum TRAb concentration (108). Thus,

Table 1 Indications for systemic glucocorticoid treatment for thyroid-associated ophthalmopathy (TAO).

\begin{tabular}{l} 
Clinical setting \\
\hline Radioactive iodine (RAI) treatment for Graves' \\
hyperthyroidism in patients with mild TAO or at \\
risk of post-RAI progression
\end{tabular}

Moderate-to-severe and active TAO

\begin{tabular}{l} 
Glucocorticoid therapy \\
\hline $\begin{array}{l}\text { Low-dose, short-term } \\
\text { prednisone (steroid }\end{array}$ \\
$\begin{array}{c}\text { High-dose intravenous } \\
\text { methylprednisolone }\end{array}$
\end{tabular}

*The two regimens are selected on the basis of the degree of risk of progression. 
glucocorticoids are potent and fast anti-inflammatory agents, but also affect several activities of the immune system that are fundamental for the development and perpetuation of TAO.

Glucocorticoids have been used for the management of TAO through different routes of administration (oral, intravenous, peribulbar/retrobulbar). Randomized clinical trials have clearly shown that intravenous glucocorticoids are more effective and better tolerated than oral glucocorticoids $(109,110)$. Therefore, although the oral route is still widely used (111), the intravenous route should be preferred (102). In moderate-to-severe and active TAO, the commonest and recommended treatment consists of 12 weekly slow infusions of methylprednisolone $(500 \mathrm{mg}$ for the first six infusions, $250 \mathrm{mg}$ for the remaining six infusions, with a cumulative dose of $4.5 \mathrm{~g}$ ) (110). The use of lower (2.5 g) or higher (7.5 g) cumulative doses is associated with a lower response rate and a higher incidence of adverse events, respectively (112). The cumulative dose can be tailored according to severity of TAO and the general conditions of the patient. The recommendation is to avoid a cumulative dose $>8 \mathrm{~g}$ and a single dose $>750 \mathrm{mg}$, because both situations are associated with higher drug toxicity (102). Treatment is contraindicated in patients with recent viral hepatitis, significant hepatic dysfunction, severe cardiovascular morbidity or psychiatric disorders; diabetes mellitus and hypertension are not absolute contraindications, but they should be controlled before starting treatment (102). This complex pretreatment work-up underscores the concept that a thorough evaluation of the patient should be carried out in specialized centers.

An ideal treatment for TAO, as well as for any other disorder, should be highly effective and hit the causative pathophysiological steps of the disease, and, at the same time, be devoid of significant short-term and long-term toxicity. If one applies this definition, glucocorticoids are not an ideal treatment for TAO. They are highly effective in inactivating TAO, that is to say that inflammation is abated by the drug. Glucocorticoids are rapid, potent and very effective in this regard. Using CAS, a very useful, although imperfect, tool for assessing inflammation, inactivation of TAO (final CAS $\leq 2 / 7$ ) has been reported in about $60 \%$ of cases in 9 randomized studies and $90 \%$ of cases in 13 non-randomized studies (103). Inactivation may occur very early (within a few weeks, but even slightly later during the intravenous glucocorticoid treatment) (113). In a large randomized clinical trial of 159 patients, CAS decreased by at least two points in more than $80 \%$ of patients receiving a cumulative dose of intravenous methylprednisolone of 5 or $7.5 \mathrm{~g}$ and about $60 \%$ in those given a cumulative dose of $2.5 \mathrm{~g}$ (112). The relatively wide variability of glucocorticoid effectiveness on inflammation may depend on the selection of patients, because treating TAO as early as possible after its onset is likely to be associated with a more effective abating of inflammation, while longstanding soft tissue changes may be congestive rather than inflammatory, related to obstacles in the lymphatic and/or venous flow, and, therefore, unresponsive to treatment. The effect of glucocorticoids on exophthalmos is less impressive, ranging from $-0.6 \mathrm{~mm}$ to $-2 \mathrm{~mm}$ decrease in three large randomized clinical trials $(109,110,112)$ the mean being -1.14 and $-1.58 \mathrm{~mm}$ in eight randomized and nine nonrandomized studies, respectively (103). Diplopia is a responsive feature, provided it is of recent onset, before fibrotic changes occur. In the large systematic review and metanalysis quoted above (103), improvement or disappearance of diplopia was found in about $60 \%$ of patients. This positive effect on eye muscle motility is more pronounced with the highest recommended dose of methylprednisolone (7.5 g) (112). Quality of life, assessed by a validated disease-specific questionnaire (114), improves substantially in 50-60\% of patients (112). The overall response rate, reported to be around $80 \%$ in two randomized clinical trials $(109,110)$, was much lower in a more recent study, probably due to selection of patients with less severe disease and relatively longer duration of TAO (112). Relapses may occur in about $7-12 \%$ of patients after discontinuation of intravenous treatment (112), but in general this effect is durable. In my clinical practice, I see patients who do not respond satisfactorily to intravenous glucocorticoid treatment, but I rarely see relapsing patients, possibly due to the use of a short tail of low-dose oral prednisone aimed to prevent rebound immune phenomena following abrupt treatment withdrawal. The possible development of dysthyroid optic neuropathy during or after intravenous glucocorticoid treatment should always be kept in mind (112). Safety is an important issue in systemic glucocorticoid treatment: morbidity and mortality in patients receiving intravenous glucocorticoids for TAO have been calculated to be 6.5 and $0.6 \%$, respectively (103). Severe hepatoxicity and major cardiovascular/cerebrovascular adverse events are in general bound to the use of a cumulative dose of methylprednisolone $>8 \mathrm{~g}$ (115). However, a recent prospective study of adverse events coded according to the standardized medical dictionary for regulatory activities showed the good tolerance and low morbidity of the commonest regimen for GO (cumulative dose, $4.5 \mathrm{~g}$ of 
methylprednisolone) (116). Nonetheless, a strict clinical and biochemical surveillance in specialized centers is required during the treatment course. In addition, proton pump inhibitors to prevent peptic ulcer and bone protection are recommended (102).

There is a substantial individual variability in the response to glucocorticoids, which does not seem to be due to glucocorticoid receptor polymorphisms (117). Indeed, there are cases of glucocorticoid-refractory TAO. It is possible that some of these cases are related to a wrong selection of patients who are no longer in the active (inflammatory) phase of the disease and, thereby, cannot benefit from treatment. What can be offered to these patients for the time being? Based on currently available evidence, the EUGOGO guidelines propose a possible combination of oral glucocorticoids and orbital radiotherapy or cyclosporine or treatment with rituximab (102). The reason to propose the oral route in the combination treatment is that evidence for the use of intravenous glucocorticoids in combination with orbital radiotherapy or cyclosporine is limited or absent. The role of orbital radiotherapy is not universally accepted (118), and also recently conflicting overview of its effectiveness have been provided $(119,120,121)$. In my 'real-life' daily practice, I use intravenous glucocorticoids with orbital radiotherapy as a second-line treatment to my (and patients') satisfaction.

Combining glucocorticoids with a second agent might improve the treatment outcome and also have a steroid-sparing effect, allowing the use of a lower dose of glucocorticoids $(122,123)$. Recent randomized clinical trials suggest that the combination of intravenous glucocorticoids with the immunosuppressant agent, mycophenolate (123) or oral glucocorticoids with azathioprine (119) provides some benefit, but clinical relevance and durability of these finding must be confirmed, also taking into account the cost/benefit ratio. In addition, because of their experimental design, these studies did not provide evidence that combination therapy allowed a step down in the dose of glucocorticoids. An old prospective case-control study failed to show any benefit at all from azathioprine monotherapy in patients with moderate-to-severe and active TAO (124). A small, single-center, retrospective study of 24 patients showed that the early combination of intravenous glucocorticoids with one or more steroid-sparing agents, mostly methotrexate, permitted the use of lower cumulative doses of methylprednisolone than those recommended by EUGOGO (125). This combination therapy did not prevent the occurrence of DON in two patients (126).

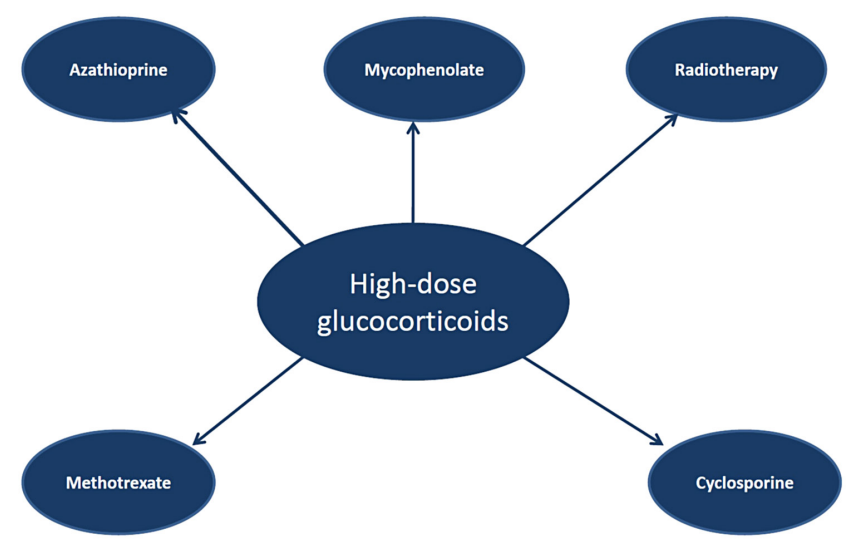

Figure 3

Possible combination of high-dose intravenous glucocorticoids with other drugs or therapies for moderate-to-severe and active TAO.

Combination therapy for TAO (Fig. 3) built up around the core represented by intravenous glucocorticoids is an interesting perspective, which requires confirmation by properly designed trials.

There is no doubt that that the major breakthrough in the neglected field of management of TAO was recently provided by the use of biologicals, in turn prompted by a better understanding of pathophysiology of the disease (15). After small, non-randomized studies, the effects of rituximab, a CD20-positive B cell-depleting monoclonal antibody, were reported in two small, singlecenter, randomized clinical trials $(76,77)$. Results were conflicting, because one study showed no difference between rituximab and placebo (76), while the other one showed that rituximab was as effective as intravenous glucocorticoids in inactivating TAO and associated with a lower rate of relapses after treatment discontinuation (77). These discrepant results might be explained by the longer duration of TAO in the first study (126). Doses as low as $100 \mathrm{mg}$ in a single shot might be equally effective compared to the higher doses used in the two randomized clinical trials (127). A recent systematic review and metaanalysis of 11 studies including 167 patients supported the promising effects of rituximab for the management of TAO (128), but large, multicenter, randomized clinical trials are needed. Tocilizumab, an anti-interleukin-6 receptor monoclonal antibody, was evaluated in a placebocontrolled, randomized clinical trial of 32 patients with moderate-to-severe and active TAO from several Spanish centers (80). Outcomes in terms of inactivation and overall improvement appeared to be significantly better compared to placebo, although it should be noted that 
in the follow-up visit at 40 weeks, differences were less impressive (80). The most impressive results were recently reported using teprotumumab, an anti-IGF1-receptor monoclonal antibody. In a large multicenter, placebocontrolled randomized clinical trial of 87 patients, teprotumumab provided impressive results in terms of overall response (69\% in in the teprotumumab group vs $20 \%$ in the placebo group), the effect on CAS was rapid, and there was an unexpected and unprecedented (with non-surgical treatments) reduction of exophthalmos, averaging $-2.46 \mathrm{~mm}$ at 24 weeks, with $40 \%$ of patients experiencing a decrease in exophthalmos of $\geq 4 \mathrm{~mm}$ (93). A subsequent post hoc analysis of the proptosis results of this study showed that 55\% of teprotumumabtreated patients had a $>3 \mathrm{~mm}$ decrease in exophthalmos, with a mean decrease of $-2.95 \mathrm{~mm}$ (94), similar to that obtained after orbital decompression (129). Surprisingly, despite the marked changes in function and appearance, the improvement in the quality of life was not very impressive $(93,130)$. Enrolled patients had severe TAO of very short duration; accordingly, it is not known whether these results can be replicated in patients with the more common phenotype (less severe TAO of a relatively longer duration). Results of the confirmatory (again, placebo-controlled) study, announced on the media as positive, have not been published yet while I am writing this article. Durability of the effects, as well as long-term safety, of tocilizumab and teprotumumab remain to be established. Other biological agents, which have the potential to be effective for TAO, include tumor necrosis factor $\alpha$ inhibitors, tyrosine kinase inhibitors, anti-CTLA-4, anti-IL-1 receptor, anti-B factor-activating factor monoclonal antibodies, but no randomized clinical trials are available to support them for the time being.

Another relevant issue is long-term safety of drugs used for the management of moderate-to-severe and active TAO. Side effects of glucocorticoids are well known, either in the short-term and long-term, and serious adverse events may occur (115), as discussed earlier. This once again underscores the concept that intravenous glucocorticoid treatment for TAO should be performed in experienced centers under strict surveillance and after a meticulous pretreatment diagnostic work-up (102). Safety is an issue also for biologicals. Rituximab, tocilizumab and teprotumumab appeared to be well tolerated in the few published studies, as glucocorticoids in the majority of cases. What do we know about long-term safety of these novel drugs? Very little (Table 2). It should be noted that in patients with RA, some of these agents have been associated with an increased risk of occurrence or reactivation of infections, including tuberculosis and hepatitis, a modest increase in the risk of lymphoma and some solid tumors, and possible aggravation or de novo occurrence of demyelinating disease (131). It can be argued that RA is a chronic disease requiring long-term therapy, whereas TAO is a self-limiting disease requiring relatively short-term therapy. This consideration is obviously correct, but it should then be applied also to the often demonized glucocorticoid treatment. And let us keep remembering that other so-called steroid-sparing agent, such as azathioprine, methotrexate, cyclosporine and mycophenolate, are not devoid of the risk of potentially serious adverse events.

Other relevant issues are costs of and access to treatment. Oral glucocorticoids are less expensive than intravenous glucocorticoids, because they do not require hospital admission. Although cost of rituximab treatment is decreasing, the other biologicals are expensive and/or not available. Although we are not dealing with large numbers of patients, because moderate-to-severe and active forms of TAO are nowadays rare, these considerations require due attention.

Trying to summarize what I have written above, I think that, for the time being, glucocorticoids, given through the intravenous route, remain the first-line treatment for moderate-to-severe and active TAO. They are effective $(109,110,132)$, and the majority of patients, if properly selected, respond to glucocorticoids. Their effectiveness is related to both general and disease-specific actions. Their general effect resides with the potent and prompt antiinflammatory action of these agents. However, they do have also immunosuppressant effects fundamental for blocking autoimmune reactions ongoing in the orbit, because they act on dendritic cells, B cells and T cells, and reduce TRAb, the purported ultimate responsible of TAO. In other words, intravenous glucocorticoids can act on the very initial steps of the cascade of events in the orbit of TAO patients, while other drugs, including tocilizumab and teprotumumab act downstream the initial events. Admittedly, intravenous glucocorticoids, according to the available literature, much more numerous than for more recently developed drugs, are imperfect, because there are patients who do not respond or relapse after treatment withdrawal, and exophthalmos is not very responsive. I believe that these limitations can be, at least partially, overcome, and their effectiveness can be improved by earlier diagnosis and prompter initiation of treatment.

For tocilizumab, teprotumumab and rituximab, the 'proof-of-principle' studies (evaluation against placebo) are available as for intravenous glucocorticoids (132), 
Table 2 General available information of therapy with high-dose glucocorticoids, rituximab, tocilizumab and teprotumumab for moderate-to-severe and TAO, as resulting from randomized clinical trials.

\begin{tabular}{|c|c|c|c|c|}
\hline & $\begin{array}{l}\text { Intravenous } \\
\text { glucocorticoids }\end{array}$ & Rituximab & Tocilizumab & Teprotumumab \\
\hline Proof-of-principle study & $\begin{array}{l}\text { More effective than } \\
\text { placebo }\end{array}$ & $\begin{array}{l}\text { Not different from } \\
\text { placebo* }\end{array}$ & $\begin{array}{l}\text { More effective than } \\
\text { placebo }\end{array}$ & $\begin{array}{l}\text { More effective than } \\
\text { placebo }\end{array}$ \\
\hline Short-term side effects & Known & Known & Known & Known \\
\hline Long-term side effects & Known & Unknown & Unknown & Unknown \\
\hline Durability & Known & Unknown & Unknown & Unknown \\
\hline $\begin{array}{l}\text { Comparison with intravenous } \\
\text { glucocorticoids }\end{array}$ & - & Yes* & No & No \\
\hline
\end{tabular}

*One small, monocentric randomized clinical trial (71) showed no difference between placebo and rituximab; another small, monocentric randomized clinical trial (72) showed similar effectiveness of intravenous glucocorticoids and rituximab in inactivating TAO and a low relapse rate with rituximab after treatment withdrawal.

but rituximab failed to prove different from placebo, whereas tocilizumab and teprotumumab appeared to modify positively the natural course of TAO, as intravenous glucocorticoids often do (97). However, while one small, single-center randomized clinical trial compared rituximab to intravenous glucocorticoids and reported the biological to be substantially equally effective in terms of inactivation of TAO and associated with a lower rate of flares, studies comparing either tocilimuzab or teprotumumab to intravenous glucocorticoids are not available. Additional studies are urgently needed in this regard. Direct comparison with intravenous glucocorticoids in series of patients with the same clinical characteristics, particularly activity, severity and, most importantly, duration of TAO (a really crucial point), and using a standardized assessment to evaluate treatment outcomes, is mandatory. It is possible that in the future, combination of intravenous glucocorticoids with one or more biologicals may improve, by targeting simultaneously different steps of the pathogenic cascade of TAO, the final prognosis of moderate-to-severe and active TAO and reduce (or abolish?) the need for rehabilitative surgery. For the time being, I remain convinced that intravenous glucocorticoids are the first-line treatment for this invalidating (although rare) disease, but I am ready to change my mind, if and when direct evidence will be provided that novel biologicals are more effective and less toxic in the long-term than intravenous glucocorticoids, compared in head-to-head trials, for the good of patients.

\section{Conclusions and perspectives}

The use of glucocorticoids in active, moderate-tosevere TAO has become commonplace and has gained widespread acceptance. Yet its benefit in this disease remains incomplete. Further its continued use has been perpetuated by the absence of better alternatives. Available evidence indicates that glucocorticoids are not always associated with an optimal disease outcome. Several biological drugs that have proven therapeutic value in other autoimmune disease are beginning to be examined for use in TAO. Another, a monoclonal antibody developed as a cancer therapy, was ineffective in neoplastic disease but was repurposed for TAO based on the physiologic plausibility of its molecular target. Teprotumumab, an inhibitor of IGF-IR, has been recently subjected to evaluation in active, moderate-to-severe TAO. Results from two placebo-controlled, prospective, multicenter trials have demonstrated remarkable effectiveness and an encouraging safety profile over a follow-up period spanning as long as 72 weeks. The trial results suggest that the drug improves proptosis, clinical activity, diplopia and quality of life. It is at least as effective as the best surgical outcomes in reducing exophthalmos, an unprecedented effect not seen with other medical treatments. We await the publication of data concerning the durability of teprotumumab effectiveness beyond 28 weeks as well as the relapse rate among responders. Thus, one of the authors (TJS who invented the concept that this and similar drugs targeting IGF-IR might be effective for active TAO) proposes that teprotumumab represents a drug likely to become first-line therapy for moderate-tosevere, active TAO. He believes that imperfect drugs such as glucocorticoids should be replaced by more effective and safer treatments as soon as they are developed and have been rigorously proven in the clinic. Further, he feels that clinically comparing teprotumumab and glucocorticoids is unwarranted and unlikely to be supported by industry, given the attendant costs of such studies. He recognizes that some practitioners in the field may remain reticent to consider the drug as first-line therapy for TAO in the 
absence of a head-to-head trial comparing it to steroids. He considers such a study as being unnecessary in light of the dramatic apparent benefit of teprotumumab. The other author (LB), although recognizing the impressive results of recent studies, remains, for the time being, skeptical about biological agents replacing glucocorticoids as first-line monotherapy for TAO and believes that further evidence must be provided. He is open minded while awaiting trials comparing the new drugs with glucocorticoids. Clearly, only the passage of time and an introduction of teprotumumab into the clinic/marketplace will determine which of the authors is correct. One author (LB) thinks that combination treatments should also be explored. In any event, both authors agree that effective and safe non-surgical treatments for $\mathrm{TAO}$ are needed and their availability may be closer than anticipated a few years ago. Improved therapies should directly benefit patients affected with this disfiguring, invalidating, potentially blinding disease.

\section{Declaration of interest}

T J S has been issued U.S. patents 6936426, 7998681, 8153121, and 8178304 covering the inhibition of IGF-I receptor as therapy for TAO. He is a consultant for River Vision and Horizon Pharma. L B has nothing to disclose.

\section{Funding}

This work was supported in part by the National Institutes of Health grants EY008976, EY11708, DK063121, 5UMIA110557 and core center for research grant EY007003 (T J S), and Ministry of Education, University and Research (MIUR, Rome, grant 2015HPMLFY_009) and the University of Insubria (L B).

\section{References}

1 Smith TJ \& Hegedus L. Graves' disease. New England Journal of Medicine 2016375 1552-1565. (https://doi.org/10.1056/ NEJMra1510030)

2 Abraham-Nordling M, Bystrom K, Torring O, Lantz M, Berg G, Calissendorff J, Nystrom HF, Jansson S, Jorneskog G, Karlsson FA et al. Incidence of hyperthyroidism in Sweden. European Journal of Endocrinology 2011165 899-905. (https://doi.org/10.1530/EJE-11-0548)

3 Bartalena L \& Fatourechi V. Extrathyroidal manifestations of Graves' disease: a 2014 update. Journal of Endocrinological Investigation 2014 37 691-700. (https://doi.org/10.1007/s40618-014-0097-2)

4 Piantanida E, Tanda ML, Lai A, Sassi L \& Bartalena L. Prevalence and natural history of Graves' orbitopathy in the XXI century. Journal of Endocrinological Investigation 201336 444-449. (https://doi. org/10.3275/8937)

5 Perros P, Zarkovic M, Azzolini C, Ayvaz G, Baldeschi L, Bartalena L, Boschi A, Bournaud C, Brix TH, Covelli D et al. PREGO (presentation of Graves' orbitopathy) study: changes in referral patterns to European Group on Graves' orbitopathy (EUGOGO) centres over the period from 2000 to 2012. British Journal of Ophthalmology 201599 1531-1535. (https://doi.org/10.1136/bjophthalmol-2015-306733)

6 Tanda ML, Piantanida E, Liparulo L, Veronesi G, Lai A, Sassi L, Pariani N, Gallo D, Azzolini C, Ferrario M et al. Prevalence and natural history of Graves' orbitopathy in a large series of patients with newly diagnosed graves' hyperthyroidism seen at a single center. Journal of Clinical Endocrinology and Metabolism 201398 1443-1449. (https://doi.org/10.1210/jc.2012-3873)

7 Perros P, Dayan CM, Dickinson AJ, Ezra D, Estcourt S, Foley P, Hickey J, Lazarus JH, MacEwen CJ, McLaren J et al. Management of patients with Graves' orbitopathy: initial assessment, management outside specialised centres and referral pathways. Clinical Medicine 201515 173-178. (https://doi.org/10.7861/clinmedicine.15-2-173)

8 Perros P, Hegedus L, Bartalena L, Marcocci C, Kahaly GJ, Baldeschi L, Salvi M, Lazarus JH, Eckstein A, Pitz S et al. Graves' orbitopathy as a rare disease in Europe: a European Group on Graves' orbitopathy (EUGOGO) position statement. Orphanet Journal of Rare Diseases 2017 12 72. (https://doi.org/10.1186/s13023-017-0625-1)

9 Bartalena L. Prevention of Graves' ophthalmopathy. Best Practice and Research: Clinical Endocrinology and Metabolism 201226 371-379. (https://doi.org/10.1016/j.beem.2011.09.004)

10 Bartalena L \& Tanda ML. Clinical practice. Graves' ophthalmopathy. New England Journal of Medicine 2009360 994-1001. (https://doi. org/10.1056/NEJMcp0806317)

11 Wiersinga WM. Graves' ophthalmopathy and dermopathy. Preface. Best Practice and Research: Clinical Endocrinology and Metabolism 2012 26 227. (https://doi.org/10.1016/j.beem.2012.01.001)

12 Campi I, Vannucchi G \& Salvi M. THERAPY of ENDOCRINE DISEASE: Endocrine dilemma: management of Graves' orbitopathy. European Journal of Endocrinology 2016175 R117-R133. (https://doi. org/10.1530/EJE-15-1164)

13 Bartalena L. Graves' orbitopathy: imperfect treatments for a rare disease. European Thyroid Journal 20132 259-269. (https://doi. org/10.1159/000356042)

14 Smith TJ. TSHR as a therapeutic target in Graves' disease. Expert Opinion on Therapeutic Targets 201721 427-432. (https://doi.org/10.1 080/14728222.2017.1288215)

15 Smith TJ \& Janssen JAMJL. Insulin-like growth factor-I receptor and thyroid-associated ophthalmopathy. Endocrine Reviews 201940 236-267. (https://doi.org/10.1210/er.2018-00066)

16 Wiersinga WM. Advances in treatment of active, moderate-to-severe Graves' ophthalmopathy. Lancet Diabetes and Endocrinology 20175 134-142. (https://doi.org/10.1016/S2213-8587(16)30046-8)

17 Rundle FF \& Wilson CW. Development and course of exophthalmos and ophthalmoplegia in Graves' disease with special reference to the effect of thyroidectomy. Clinical Science 19455 177-194.

18 Smith TJ. Rationale for therapeutic targeting insulin-like growth factor-1 receptor and bone marrow-derived fibrocytes in thyroidassociated ophthalmopathy. Expert Review of Ophthalmology 201611 77-79. (https://doi.org/10.1586/17469899.2016.1164598)

19 Moshkelgosha S, So PW, Deasy N, Diaz-Cano S \& Banga JP. Cutting edge: retrobulbar inflammation, adipogenesis, and acute orbital congestion in a preclinical female mouse model of Graves' orbitopathy induced by thyrotropin receptor plasmid-in vivo electroporation. Endocrinology 2013154 3008-3015. (https://doi. org/10.1210/en.2013-1576)

20 Adams DD, Purves HD \& Sirett NE. The response of hypophysectomized mice to injections of human serum containing long-acting thyroid stimulator. Endocrinology 196168 154-155. (https://doi.org/10.1210/endo-68-1-154)

21 Diana T, Olivo PD \& Kahaly GJ. Thyrotropin receptor blocking antibodies. Hormone and Metabolic Research 201850 853-862. (https://doi.org/10.1055/a-0723-9023)

22 Ehlers M, Allelein S \& Schott M. TSH-receptor autoantibodies: pathophysiology, assay methods, and clinical applications. Minerva Endocrinologica 201843 323-332. (https://doi.org/10.23736/S03911977.17.02791-2)

23 Pritchard J, Han R, Horst N, Cruikshank WW \& Smith TJ. Immunoglobulin activation of $\mathrm{T}$ cell chemoattractant expression in fibroblasts from patients with Graves' disease is mediated through the insulin-like growth factor I receptor pathway. Journal 
of Immunology 2003 170 6348-6354. (https://doi.org/10.4049/ jimmunol.170.12.6348)

24 Marino M, Rotondo Dottore G, Ionni I, Lanzolla G, Sabini E, Ricci D, Sframeli A, Mazzi B, Menconi F, Latrofa F et al. Serum antibodies against the insulin-like growth factor-1 receptor (IGF-1R) in Graves' disease and Graves' orbitopathy. Journal of Endocrinological Investigation 201942 471-480. (https://doi. org/10.1007/s40618-018-0943-8)

25 Varewijck AJ, Boelen A, Lamberts SW, Fliers E, Hofland LJ, Wiersinga WM \& Janssen JA. Circulating IgGs may modulate IGF-I receptor stimulating activity in a subset of patients with Graves' ophthalmopathy. Journal of Clinical Endocrinology and Metabolism 201398 769-776. (https://doi.org/10.1210/jc.2012-2270)

26 Pritchard J, Tsui S, Horst N, Cruikshank WW \& Smith TJ. Synovial fibroblasts from patients with rheumatoid arthritis, like fibroblasts from Graves' disease, express high levels of IL-16 when treated with Igs against insulin-like growth factor-1 receptor. Journal of Immunology 2004173 3564-3569. (https://doi.org/10.4049/ jimmunol.173.5.3564)

27 Minich WB, Dehina N, Welsink T, Schwiebert C, Morgenthaler NG Kohrle J, Eckstein A \& Schomburg L. Autoantibodies to the IGF1 receptor in Graves' orbitopathy. Journal of Clinical Endocrinology and Metabolism 201398 752-760. (https://doi.org/10.1210/jc.2012-1771)

28 Krieger CC, Neumann S, Place RF, Marcus-Samuels B \& Gershengorn MC. Bidirectional TSH and IGF-1 receptor cross talk mediates stimulation of hyaluronan secretion by Graves' disease immunoglobins. Journal of Clinical Endocrinology and Metabolism 2015 100 1071-1077. (https://doi.org/10.1210/jc.2014-3566)

29 Tsui S, Naik V, Hoa N, Hwang CJ, Afifiyan NF, Sinha Hikim A, Gianoukakis AG, Douglas RS \& Smith TJ. Evidence for an association between thyroid-stimulating hormone and insulin-like growth factor 1 receptors: a tale of two antigens implicated in Graves' disease. Journal of Immunology 2008181 4397-4405. (https://doi.org/10.4049/ jimmunol.181.6.4397)

30 Douglas RS \& Smith TJ. Thyroid related orbitopathy: new immunologic concepts and future implications. In Oculoplastics and Orbit. Essentials in Ophthalmology, pp 123-141. Eds R Guthoff \& J Katowitz. Berlin: Springer-Verlag, 2007.

31 Douglas RS, Naik V, Hwang CJ, Afifiyan NF, Gianoukakis AG, Sand D, Kamat $S$ \& Smith TJ. B cells from patients with Graves' disease aberrantly express the IGF-1 receptor: implications for disease pathogenesis. Journal of Immunology 2008181 5768-5774. (https:// doi.org/10.4049/jimmunol.181.8.5768)

32 Weetman AP, Cohen S, Gatter KC, Fells P \& Shine B. Immunohistochemical analysis of the retrobulbar tissues in Graves' ophthalmopathy. Clinical and Experimental Immunology 198975 222-227.

33 van Steensel L, Paridaens D, van Meurs M, van Hagen PM, van den Bosch WA, Kuijpers RW, Drexhage HA, Hooijkaas H \& Dik WA. Orbitinfiltrating mast cells, monocytes, and macrophages produce PDGF isoforms that orchestrate orbital fibroblast activation in Graves' ophthalmopathy. Journal of Clinical Endocrinology and Metabolism 201297 E400-E408. (https://doi.org/10.1210/jc.2011-2697)

34 Douglas RS, Afifiyan NF, Hwang CJ, Chong K, Haider U, Richards P, Gianoukakis AG \& Smith TJ. Increased generation of fibrocytes in thyroid-associated ophthalmopathy. Journal of Clinical Endocrinology and Metabolism 201095 430-438. (https://doi. org/10.1210/jc.2009-1614)

35 Wang Y \& Smith TJ. Current concepts in the molecular pathogenesis of thyroid-associated ophthalmopathy. Investigative Ophthalmology and Visual Science 201455 1735-1748. (https://doi.org/10.1167/ iovs.14-14002)

36 Bucala R, Spiegel LA, Chesney J, Hogan M \& Cerami A. Circulating fibrocytes define a new leukocyte subpopulation that mediates tissue repair. Molecular Medicine 19941 71-81. (https://doi.org/10.1007/ BF03403533)
37 Smith TJ. Potential roles of CD34+ fibrocytes masquerading as orbital fibroblasts in thyroid-associated ophthalmopathy. Journal of Clinical Endocrinology and Metabolism 2019104 581-594. (https://doi. org/10.1210/jc.2018-01493)

38 Fernando R, Atkins S, Raychaudhuri N, Lu Y, Li B, Douglas RS \& Smith TJ. Human fibrocytes coexpress thyroglobulin and thyrotropin receptor. PNAS 2012109 7427-7432. (https://doi.org/10.1073/ pnas.1202064109)

39 Fernando R, Lu Y, Atkins SJ, Mester T, Branham K \& Smith TJ. Expression of thyrotropin receptor, thyroglobulin, sodium-iodide symporter, and thyroperoxidase by fibrocytes depends on AIRE. Journal of Clinical Endocrinology and Metabolism 201499 E1236E1244. (https://doi.org/10.1210/jc.2013-4271)

$40 \mathrm{Li}$ B \& Smith TJ. Regulation of IL-1 receptor antagonist by TSH in fibrocytes and orbital fibroblasts. Journal of Clinical Endocrinology and Metabolism 201499 E625-E633. (https://doi.org/10.1210/jc.20133977)

41 Raychaudhuri N, Fernando R \& Smith TJ. Thyrotropin regulates IL-6 expression in CD34+ fibrocytes: clear delineation of its cAMP-independent actions. PLoS ONE 20138 e75100. (https://doi. org/10.1371/journal.pone.0075100)

42 Lu Y, Atkins SJ, Fernando R, Trierweiler A, Mester T, Grisolia ABD, Mou P, Novaes P \& Smith TJ. CD34- orbital fibroblasts from patients with thyroid-associated ophthalmopathy modulate TNFalpha expression in CD34+ fibroblasts and fibrocytes. Investigative Ophthalmology and Visual Science 201859 2615-2622. (https://doi. org/10.1167/iovs.18-23951)

43 Hong KM, Belperio JA, Keane MP, Burdick MD \& Strieter RM. Differentiation of human circulating fibrocytes as mediated by transforming growth factor-beta and peroxisome proliferatoractivated receptor gamma. Journal of Biological Chemistry 2007282 22910-22920. (https://doi.org/10.1074/jbc.M703597200)

44 Furmaniak J, Sanders J, Young S, Kabelis K, Sanders P, Evans M, Clark J, Wilmot J \& Rees Smith B. In vivo effects of a human thyroidstimulating monoclonal autoantibody (M22) and a human thyroidblocking autoantibody (K1-70). Auto Immun Highlights 20123 19-25. (https://doi.org/10.1007/s13317-011-0025-9)

45 Shao DD, Suresh R, Vakil V, Gomer RH \& Pilling D. Pivotal advance: Th-1 cytokines inhibit, and Th-2 cytokines promote fibrocyte differentiation. Journal of Leukocyte Biology 200883 1323-1333. (https://doi.org/10.1189/jlb.1107782)

46 Pilling D, Vakil V, Cox N \& Gomer RH. TNF-alpha-stimulated fibroblasts secrete lumican to promote fibrocyte differentiation. PNAS 2015112 11929-11934. (https://doi.org/10.1073/pnas.1507387112)

47 Pilling D, Zheng Z, Vakil V \& Gomer RH. Fibroblasts secrete Slit2 to inhibit fibrocyte differentiation and fibrosis. PNAS 2014111 18291-18296. (https://doi.org/10.1073/pnas.1417426112)

48 Cox N, Pilling D \& Gomer RH. Distinct Fcgamma receptors mediate the effect of serum amyloid p on neutrophil adhesion and fibrocyte differentiation. Journal of Immunology 2014193 1701-1708. (https:// doi.org/10.4049/jimmunol.1400281)

49 Fernando R, Grisolia ABD, Lu Y, Atkins S \& Smith TJ. Slit2 modulates the inflammatory phenotype of orbit-infiltrating fibrocytes in Graves' disease. Journal of Immunology 2018200 3942-3949. (https:// doi.org/10.4049/jimmunol.1800259)

50 Copeman WS. Treatment of true rheumatoid arthritis by blood transfusion and insulin. BMJ 19312 1130-1132. (https://doi. org/10.1136/bmj.2.3702.1130)

51 Novotny H. Autotransplantation of joint capsule, an attempt to desensitize patients suffering from rheumatoid arthritis. Acta medica Scandinavica 1948129 524-546. (https://doi. org/10.1111/j.0954-6820.1948.tb09324.x)

52 Weinblatt ME, Kremer JM, Bankhurst AD, Bulpitt KJ, Fleischmann RM, Fox RI, Jackson CG, Lange M \& Burge DJ. A trial of etanercept, a recombinant tumor necrosis factor receptor:Fc fusion protein, in patients with rheumatoid arthritis receiving 
methotrexate. New England Journal of Medicine 1999340 253-259. (https://doi.org/10.1056/NEJM199901283400401)

53 den Broeder AA, Joosten LA, Saxne T, Heinegard D, Fenner H, Miltenburg AM, Frasa WL, van Tits LJ, Buurman WA, van Riel PL et al. Long term anti-tumour necrosis factor alpha monotherapy in rheumatoid arthritis: effect on radiological course and prognostic value of markers of cartilage turnover and endothelial activation. Annals of the Rheumatic Diseases 200261 311-318. (https://doi. org/10.1136/ard.61.4.311)

54 Weinblatt ME, Keystone EC, Furst DE, Moreland LW, Weisman MH, Birbara CA, Teoh LA, Fischkoff SA \& Chartash EK. Adalimumab, a fully human anti-tumor necrosis factor alpha monoclonal antibody, for the treatment of rheumatoid arthritis in patients taking concomitant methotrexate: the ARMADA trial. Arthritis and Rheumatism 200348 35-45. (https://doi.org/10.1002/art.10697)

55 Kaplan M. Eculizumab (Alexion). Current Opinion in Investigational Drugs 20023 1017-1023.

56 Papadopoulos MC, Bennett JL \& Verkman AS. Treatment of neuromyelitis optica: state-of-the-art and emerging therapies. Nature Reviews: Neurology 201410 493-506. (https://doi.org/10.1038/ nrneurol.2014.141)

57 Pittock SJ, Berthele A, Fujihara K, Kim HJ, Levy M, Palace J, Nakashima I, Terzi M, Totolyan N, Viswanathan S et al. Eculizumab in Aquaporin-4-Positive neuromyelitis optica spectrum disorder. New England Journal of Medicine 2019381 614-625. (https://doi. org/10.1056/NEJMoa1900866)

58 Karnell JL, Rieder SA, Ettinger R \& Kolbeck R. Targeting the CD40CD40L pathway in autoimmune diseases: humoral immunity and beyond. Advanced Drug Delivery Reviews 2018. (https://doi. org/10.1016/j.addr.2018.12.005)

59 Kishimoto T, Akira S \& Taga T. Interleukin-6 and its receptor: a paradigm for cytokines. Science 1992258 593-597. (https://doi. org/10.1126/science.1411569)

60 Nakahara H \& Nishimoto N. Anti-interleukin-6 receptor antibody therapy in rheumatic diseases. Endocrine, Metabolic and Immune Disorders Drug Targets 20066 373-381. (https://doi. org/10.2174/187153006779025694)

61 Mihara M, Kasutani K, Okazaki M, Nakamura A, Kawai S, Sugimoto M, Matsumoto Y \& Ohsugi Y. Tocilizumab inhibits signal transduction mediated by both mIL-6R and sIL-6R, but not by the receptors of other members of IL-6 cytokine family. International Immunopharmacology 20055 1731-1740. (https://doi.org/10.1016/j.intimp.2005.05.010)

62 Strand V, Dimonaco S, Tuckwell K, Klearman M, Collinson N \& Stone JH. Health-related quality of life in patients with giant cell arteritis treated with tocilizumab in a phase 3 randomised controlled trial. Arthritis Research and Therapy 201921 64. (https://doi. org/10.1186/s13075-019-1837-7)

63 Paul-Pletzer K. Tocilizumab: blockade of interleukin-6 signaling pathway as a therapeutic strategy for inflammatory disorders. Drugs of Today 200642 559-576. (https://doi.org/10.1358/ dot.2006.42.9.1025692)

64 Shima Y. The benefits and prospects of interleukin-6 inhibitor on systemic sclerosis. Modern Rheumatology 201929 294-301. (https:// doi.org/10.1080/14397595.2018.1559909)

65 Illei GG, Shirota Y, Yarboro CH, Daruwalla J, Tackey E, Takada K, Fleisher T, Balow JE \& Lipsky PE. Tocilizumab in systemic lupus erythematosus: data on safety, preliminary efficacy, and impact on circulating plasma cells from an open-label phase I dosage-escalation study. Arthritis and Rheumatism 201062 542-552. (https://doi. org/10.1002/art.27221)

66 Genovese MC, Kremer JM, van Vollenhoven RF, Alten R, Scali JJ, Kelman A, Dimonaco S \& Brockwell L. Transaminase levels and hepatic events during tocilizumab treatment: pooled analysis of long-term clinical trial safety data in rheumatoid arthritis. Arthritis and Rheumatology 201769 1751-1761. (https://doi.org/10.1002/ art.40176)
67 Scott SD. Rituximab: a new therapeutic monoclonal antibody for non-Hodgkin's lymphoma. Cancer Practice 19986 195-197. (https:// doi.org/10.1046/j.1523-5394.1998.006003195.x)

68 Franks SE, Getahun A, Hogarth PM \& Cambier JC. Targeting B cells in treatment of autoimmunity. Current Opinion in Immunology 2016 43 39-45. (https://doi.org/10.1016/j.coi.2016.09.003)

69 Hasselbalch HC. B-cell depletion with rituximab-a targeted therapy for Graves' disease and autoimmune thyroiditis. Immunology Letters 200388 85-86. (https://doi.org/10.1016/S0165-2478(03)00032-4)

70 Salvi M, Vannucchi G, Campi I, Rossi S, Bonara P, Sbrozzi F, Guastella C, Avignone S, Pirola G, Ratiglia R et al. Efficacy of rituximab treatment for thyroid-associated ophthalmopathy as a result of intraorbital B-cell depletion in one patient unresponsive to steroid immunosuppression. European Journal of Endocrinology 2006 154 511-517. (https://doi.org/10.1530/eje.1.02119)

71 El Fassi D, Nielsen CH, Hasselbalch HC \& Hegedus L. The rationale for B lymphocyte depletion in Graves' disease. Monoclonal anti-CD20 antibody therapy as a novel treatment option. European Journal of Endocrinology $2006 \mathbf{1 5 4}$ 623-632. (https://doi.org/10.1530/ eje.1.02140)

72 Salvi M, Vannucchi G, Campi I, Curro N, Dazzi D, Simonetta S, Bonara P, Rossi S, Sina C, Guastella C et al. Treatment of Graves' disease and associated ophthalmopathy with the anti-CD20 monoclonal antibody rituximab: an open study. European Journal of Endocrinology 2007156 33-40. (https://doi.org/10.1530/eje.1.02325)

73 El Fassi D, Nielsen CH, Bonnema SJ, Hasselbalch HC \& Hegedus L. B lymphocyte depletion with the monoclonal antibody rituximab in Graves' disease: a controlled pilot study. Journal of Clinical Endocrinology and Metabolism 200792 1769-1772. (https://doi. org/10.1210/jc.2006-2388)

74 Cole M, Hynes AM, Howel D, Hall L, Abinun M, Allahabadia A, Barrett T, Boelaert K, Drake AJ, Dimitri P et al. Adjuvant rituximab, a potential treatment for the young patient with Graves' hyperthyroidism (RiGD): study protocol for a single-arm, singlestage, phase II trial. BMJ Open 20199 e024705. (https://doi. org/10.1136/bmjopen-2018-024705)

75 Smith TJ. B cell depletion in Graves' disease: the right answer to the wrong question? Journal of Clinical Endocrinology and Metabolism 2007 92 1620-1622. (https://doi.org/10.1210/jc.2007-0463)

76 Stan MN, Garrity JA, Carranza Leon BG, Prabin T, Bradley EA \& Bahn RS. Randomized controlled trial of rituximab in patients with Graves' orbitopathy. Journal of Clinical Endocrinology and Metabolism 2015100 432-441. (https://doi.org/10.1210/jc.2014-2572)

77 Salvi M, Vannucchi G, Curro N, Campi I, Covelli D, Dazzi D, Simonetta S, Guastella C, Pignataro L, Avignone S et al. Efficacy of B-cell targeted therapy with rituximab in patients with active moderate to severe Graves' orbitopathy: a randomized controlled study. Journal of Clinical Endocrinology and Metabolism 2015100 422-431. (https://doi.org/10.1210/jc.2014-3014)

78 Atzeni F, Turiel M, Capsoni F, Doria A, Meroni P \& Sarzi-Puttini P. Autoimmunity and anti-TNF-alpha agents. Annals of the New York Academy of Sciences 20051051 559-569. (https://doi.org/10.1196/ annals.1361.100)

79 Perez-Moreiras JV, Alvarez-Lopez A \& Gomez EC. Treatment of active corticosteroid-resistant graves' orbitopathy. Ophthalmic Plastic and Reconstructive Surgery 201430 162-167. (https://doi.org/10.1097/ IOP.0000000000000037)

80 Perez-Moreiras JV, Gomez-Reino JJ, Maneiro JR, Perez-Pampin E, Romo Lopez A, Rodriguez Alvarez FM, Castillo Laguarta JM, Del Estad Cabello A, Gessa Sorroche M, Espana Gregori E et al. Efficacy of tocilizumab in patients with moderate-to-severe corticosteroidresistant graves orbitopathy: a randomized clinical trial. American Journal of Ophthalmology 2018195 181-190. (https://doi. org/10.1016/j.ajo.2018.07.038)

81 Bahn RS, Dutton CM, Natt N, Joba W, Spitzweg C \& Heufelder AE. Thyrotropin receptor expression in Graves' orbital 
adipose/connective tissues: potential autoantigen in Graves' ophthalmopathy. Journal of Clinical Endocrinology and Metabolism 199883 998-1002. (https://doi.org/10.1210/jcem.83.3.4676)

82 Smith TJ. TSH-receptor-expressing fibrocytes and thyroid-associated ophthalmopathy. Nature Reviews: Endocrinology 201511 171-181. (https://doi.org/10.1038/nrendo.2014.226)

83 Jaschke H, Neumann S, Moore S, Thomas CJ, Colson AO, Costanzi S, Kleinau G, Jiang JK, Paschke R, Raaka BM et al. A low molecular weight agonist signals by binding to the transmembrane domain of thyroid-stimulating hormone receptor (TSHR) and luteinizing hormone/chorionic gonadotropin receptor (LHCGR). Journal of Biological Chemistry 2006281 9841-9844. (https://doi.org/10.1074/ jbc.C600014200)

84 Neumann S, Eliseeva E, McCoy JG, Napolitano G, Giuliani C, Monaco F, Huang W \& Gershengorn MC. A new small-molecule antagonist inhibits Graves' disease antibody activation of the TSH receptor. Journal of Clinical Endocrinology and Metabolism 201196 548-554. (https://doi.org/10.1210/jc.2010-1935)

85 Neumann S, Nir EA, Eliseeva E, Huang W, Marugan J, Xiao J, Dulcey AE \& Gershengorn MC. A selective TSH receptor antagonist inhibits stimulation of thyroid function in female mice. Endocrinology 2014155 310-314. (https://doi.org/10.1210/en.2013-1835)

86 Sanders J, Allen F, Jeffreys J, Bolton J, Richards T, Depraetere H, Nakatake N, Evans M, Kiddie A, Premawardhana LD et al. Characteristics of a monoclonal antibody to the thyrotropin receptor that acts as a powerful thyroid-stimulating autoantibody antagonist. Thyroid 200515 672-682. (https://doi.org/10.1089/thy.2005.15.672)

87 Chen CR, McLachlan SM \& Rapoport B. A monoclonal antibody with thyrotropin (TSH) receptor inverse agonist and TSH antagonist activities binds to the receptor hinge region as well as to the leucinerich domain. Endocrinology 2009150 3401-3408. (https://doi. org/10.1210/en.2008-1800)

88 Sanders J, Miguel RN, Furmaniak J \& Smith BR. TSH receptor monoclonal antibodies with agonist, antagonist, and inverse agonist activities. Methods in Enzymology 2010485 393-420. (https://doi. org/10.1016/B978-0-12-381296-4.00022-1)

89 Tramontano D, Cushing GW, Moses AC \& Ingbar SH. Insulin-like growth factor-I stimulates the growth of rat thyroid cells in culture and synergizes the stimulation of DNA synthesis induced by TSH and Graves'-IgG. Endocrinology 1986119 940-942. (https://doi. org/10.1210/endo-119-2-940)

90 Weightman DR, Perros P, Sherif IH \& Kendall-Taylor P. Autoantibodies to IGF-1 binding sites in thyroid associated ophthalmopathy. Autoimmunity 199316 251-257. (https://doi. org/10.3109/08916939309014643)

91 Smith TJ \& Douglas RS. Pathophysiology of graves' orbitopathy. In Albert and Jakobiec's Principles and Practice of Ophthalmology, 3rd ed., pp 2913-2926. Eds DM Albert, JW Miller, DT Azar \& B Blodi. Philadelphia, PA: Saunders-Elsevier, 2008.

92 Chmielowski B. Insulin-like growth factor 1 receptor inhibitors: where do we come from? What are we? Where are we going? Cancer 2014120 2384-2387. (https://doi.org/10.1002/cncr.28727)

93 Smith TJ, Kahaly GJ, Ezra DG, Fleming JC, Dailey RA, Tang RA, Harris GJ, Antonelli A, Salvi M, Goldberg RA et al. Teprotumumab for thyroid-associated ophthalmopathy. New England Journal of Medicine 2017376 1748-1761. (https://doi.org/10.1056/NEJMoa1614949)

94 Douglas RS. Teprotumumab, an insulin-like growth factor-1 receptor antagonist antibody, in the treatment of active thyroid eye disease: a focus on proptosis. Eye 201933 183-190. (https://doi.org/10.1038/ s41433-018-0321-y)

95 Rootman DB. Orbital decompression for thyroid eye disease. Survey of Ophthalmology 201863 86-104. (https://doi.org/10.1016/j. survophthal.2017.03.007)

96 Holthoff HP, Li Z, Fassbender J, Reimann A, Adler K, Munch G \& Ungerer M. Cyclic peptides for effective treatment in a longterm model of Graves disease and orbitopathy in female mice.
Endocrinology 2017158 2376-2390. (https://doi.org/10.1210/ en.2016-1845)

97 Fassbender J, Holthoff HP, Li Z \& Ungerer M. Therapeutic effects of short cyclic and combined epitope peptides in a long-term model of Graves' disease and orbitopathy. Thyroid 201929 258-267. (https:// doi.org/10.1089/thy.2018.0326)

98 Jansson L, Vrolix K, Jahraus A, Martin KF \& Wraith DC. Immunotherapy with apitopes blocks the immune response to TSH receptor in HLA-DR transgenic mice. Endocrinology 2018159 3446-3457. (https://doi.org/10.1210/en.2018-00306)

99 Pearce SHS, Dayan C, Wraith DC, Barrell K, Olive N, Jansson L, Walker-Smith T, Carnegie C, Martin KF, Boelaert K et al. Antigenspecific immunotherapy with thyrotropin receptor peptides in graves' hyperthyroidism: a phase I study. Thyroid 201929 10031011. (https://doi.org/10.1089/thy.2019.0036)

100 Bartalena L, Pinchera A \& Marcocci C. Management of Graves' ophthalmopathy: reality and perspectives. Endocrine Reviews 200021 168-199. (https://doi.org/10.1210/edrv.21.2.0393)

101 Shiber S, Stiebel-Kalish H, Shimon I, Grossman A \& Robenshtok E. Glucocorticoid regimens for prevention of Graves' ophthalmopathy progression following radioiodine treatment: systematic review and meta-analysis. Thyroid 201424 1515-1523. (https://doi.org/10.1089/ thy.2014.0218)

102 Bartalena L, Baldeschi L, Boboridis K, Eckstein A, Kahaly GJ, Marcocci C, Perros P, Salvi M, Wiersinga WM \& European Group on Graves. The 2016 European Thyroid Association/European Group on Graves' Orbitopathy guidelines for the management of Graves' orbitopathy. European Thyroid Journal 20165 9-26. (https://doi. org/10.1159/000443828)

103 Zang S, Ponto KA \& Kahaly GJ. Clinical review: intravenous glucocorticoids for Graves' orbitopathy: efficacy and morbidity. Journal of Clinical Endocrinology and Metabolism 201196 320-332. (https://doi.org/10.1210/jc.2010-1962)

104 Barnes PJ. Glucocorticosteroids. Handbook of Experimental Pharmacology 2017237 93-115. (https://doi. org/10.1007/164_2016_62)

105 Schwartz N, Verma A, Bivens CB, Schwartz Z \& Boyan BD. Rapid steroid hormone actions via membrane receptors. Biochimica and Biophysica Acta 20161863 2289-2298. (https://doi.org/10.1016/j. bbamcr.2016.06.004)

106 Oppong E \& Cato AC. Effects of glucocorticoids in the immune system. Advances in Experimental Medicine and Biology 2015872 217-233. (https://doi.org/10.1007/978-1-4939-2895-8_9)

107 Suda T, Chida K, Matsuda H, Hashizume H, Ide K, Yokomura K, Suzuki K, Kuwata H, Miwa S, Nakano H et al. High-dose intravenous glucocorticoid therapy abrogates circulating dendritic cells. Journal of Allergy and Clinical Immunology 2003112 1237-1239. (https://doi. org/10.1016/j.jaci.2003.09.028)

108 Kubota S, Ohye H, Nishihara E, Kudo T, Ito M, Fukata S, Amino N, Kuma K \& Miyauchi A. Effect of high dose methylprednisolone pulse therapy followed by oral prednisolone administration on the production of anti-TSH receptor antibodies and clinical outcome in Graves' disease. Endocrine Journal 200552 735-741. (https://doi. org/10.1507/endocrj.52.735)

109 Marcocci C, Bartalena L, Tanda ML, Manetti L, Dell'Unto E, Rocchi R, Barbesino G, Mazzi B, Bartolomei MP, Lepri P et al. Comparison of the effectiveness and tolerability of intravenous or oral glucocorticoids associated with orbital radiotherapy in the management of severe Graves' ophthalmopathy: results of a prospective, single-blind, randomized study. Journal of Clinical Endocrinology and Metabolism 200186 3562-3567. (https://doi. org/10.1210/jcem.86.8.7737)

110 Kahaly GJ, Pitz S, Hommel G \& Dittmar M. Randomized, single blind trial of intravenous versus oral steroid monotherapy in Graves' orbitopathy. Journal of Clinical Endocrinology and Metabolism 200590 5234-5240. (https://doi.org/10.1210/jc.2005-0148) 
111 Perumal B \& Meyer DR. Treatment of severe thyroid eye disease: a survey of the American Society of Ophthalmic Plastic and Reconstructive Surgery (ASOPRS). Ophthalmic Plastic and Reconstructive Surgery 201531 127-131. (https://doi.org/10.1097/ IOP.0000000000000216)

112 Bartalena L, Krassas GE, Wiersinga W, Marcocci C, Salvi M, Daumerie C, Bournaud C, Stahl M, Sassi L, Veronesi G et al. Efficacy and safety of three different cumulative doses of intravenous methylprednisolone for moderate to severe and active Graves' orbitopathy. Journal of Clinical Endocrinology and Metabolism 201297 4454-4463. (https://doi.org/10.1210/jc.2012-2389)

113 Bartalena L, Veronesi G, Krassas GE, Wiersinga WM, Marcocci C, Marino M, Salvi M, Daumerie C, Bournaud C, Stahl M et al. Does early response to intravenous glucocorticoids predict the final outcome in patients with moderate-to-severe and active Graves' orbitopathy? Journal of Endocrinological Investigation 201740 547-553. (https://doi.org/10.1007/s40618-017-0608-z)

114 Terwee CB, Dekker FW, Mourits MP, Gerding MN, Baldeschi L, Kalmann R, Prummel MF \& Wiersinga WM. Interpretation and validity of changes in scores on the Graves' ophthalmopathy quality of life questionnaire (GO-QOL) after different treatments. Clinical Endocrinology 200154 391-398. (https://doi.org/10.1046/j.13652265.2001.01241.x)

115 Marcocci C, Watt T, Altea MA, Rasmussen AK, Feldt-Rasmussen U, Orgiazzi J, Bartalena L \& European Group of Graves' Orbitopathy. Fatal and non-fatal adverse events of glucocorticoid therapy for Graves' orbitopathy: a questionnaire survey among members of the European Thyroid Association. European Journal of Endocrinology 2012 166 247-253. (https://doi.org/10.1530/EJE-11-0779)

116 Riedl M, Kolbe E, Kampmann E, Kramer I \& Kahaly GJ. Prospectively recorded and MedDRA-coded safety data of intravenous methylprednisolone therapy in Graves' orbitopathy. Journal of Endocrinological Investigation 201538 177-182. (https://doi. org/10.1007/s40618-014-0227-x)

117 Vannucchi G, Covelli D, Campi I, Origo D, Curro N, Cirello V, Dazzi D, Beck-Peccoz P \& Salvi M. The therapeutic outcome to intravenous steroid therapy for active Graves' orbitopathy is influenced by the time of response but not polymorphisms of the glucocorticoid receptor. European Journal of Endocrinology 2014170 55-61. (https://doi.org/10.1530/EJE-13-0611)

118 Tanda ML \& Bartalena L. Efficacy and safety of orbital radiotherapy for graves' orbitopathy. Journal of Clinical Endocrinology and Metabolism 201297 3857-3865. (https://doi.org/10.1210/jc.2012-2758)

119 Oeverhaus M, Witteler T, Lax H, Esser J, Fuhrer D \& Eckstein A. Combination therapy of intravenous steroids and orbital irradiation is more effective than intravenous steroids alone in patients with Graves' orbitopathy. Hormone and Metabolic Research 201749 739-747. (https://doi.org/10.1055/s-0043-116945)

120 Rajendram R, Taylor PN, Wilson VJ, Harris N, Morris OC, Tomlinson M, Yarrow S, Garrott H, Herbert HM, Dick AD et al. Combined immunosuppression and radiotherapy in thyroid eye disease (CIRTED): a multicentre, 2 × 2 factorial, double-blind, randomised controlled trial. Lancet: Diabetes and Endocrinology 20186 299-309. (https://doi.org/10.1016/S2213-8587(18)30021-4)

121 Godfrey KJ \& Kazim M. Radiotherapy for active thyroid eye disease. Ophthalmic Plastic and Reconstructive Surgery 201834 (4S Supplement 1) S98-S104. (https://doi.org/10.1097/IOP.0000000000001074)

122 Tanda ML, Piantanida E, Masiello E, Cusini C \& Bartalena L. Can combination of glucocorticoids with other immunosoppressive drugs reduce the cumulative dose of glucocorticoids for moderateto-severe and active Graves' orbitopathy? Journal of Endocrinological Investigation 201942 351-352. (https://doi.org/10.1007/s40618019-01015-8)

123 Salvi M \& Covelli D. Combined immunosuppressants and less steroids in active graves' orbitopathy? Clinical Endocrinology 201990 525-527. (https://doi.org/10.1111/cen.13917)

124 Perros P, Weightman DR, Crombie AL \& Kendall-Taylor P. Azathioprine in the treatment of thyroid-associated ophthalmopathy. Acta Endocrinologica 1990122 8-12. (https://doi. org/10.1530/acta.0.1220008)

125 Sipkova Z, Insull EA, David J, Turner HE, Keren S \& Norris JH. Early use of steroid-sparing agents in the inactivation of moderate-tosevere active thyroid eye disease: a step-down approach. Clinical Endocrinology 201889 834-839. (https://doi.org/10.1111/cen.13834)

126 Stan MN \& Salvi M. MANAGEMENT of ENDOCRINE DISEASE: Rituximab therapy for Graves' orbitopathy - lessons from randomized control trials. European Journal of Endocrinology $2017 \mathbf{1 7 6}$ R101-R109. (https://doi.org/10.1530/EJE-16-0552)

127 Salvi M, Vannucchi G, Curro N, Introna M, Rossi S, Bonara P, Covelli D, Dazzi D, Guastella C, Pignataro L et al. Small dose of rituximab for graves orbitopathy: new insights into the mechanism of action. Archives of Ophthalmology 2012130 122-124. (https://doi. org/10.1001/archopthalmol.2011.1215)

128 Wang C, Ning Q, Jin K, Xie J \& Ye J. Does rituximab improve clinical outcomes of patients with thyroid-associated ophthalmopathy? A systematic review and meta-analysis. BMC Ophthalmology 201818 46. (https://doi.org/10.1186/s12886-018-0679-4)

129 Rootman DB, Golan S, Pavlovich P \& Rootman J. Postoperative changes in strabismus, ductions, exophthalmometry, and eyelid retraction after orbital decompression for thyroid orbitopathy. Ophthalmic Plastic and Reconstructive Surgery 201733 289-293. (https://doi.org/10.1097/IOP.0000000000000758)

130 Piantanida E \& Bartalena L. Teprotumumab: a new avenue for the management of moderate-to-severe and active Graves' orbitopathy? Journal of Endocrinological Investigation 201740 885-887. (https://doi. org/10.1007/s40618-017-0717-8)

131 Rubbert-Roth A. Assessing the safety of biologic agents in patients with rheumatoid arthritis. Rheumatology 201251 (Supplement 5) v38-v47. (https://doi.org/10.1093/rheumatology/kes114)

132 van Geest RJ, Sasim IV, Koppeschaar HP, Kalmann R, Stravers SN, Bijlsma WR \& Mourits MP. Methylprednisolone pulse therapy for patients with moderately severe Graves' orbitopathy: a prospective, randomized, placebo-controlled study. European Journal of Endocrinology 2008158 229-237. (https://doi.org/10.1530/EJE-07-0558)

Received 23 May 2019

Revised version received 12 July 2019

Accepted 30 July 2019 